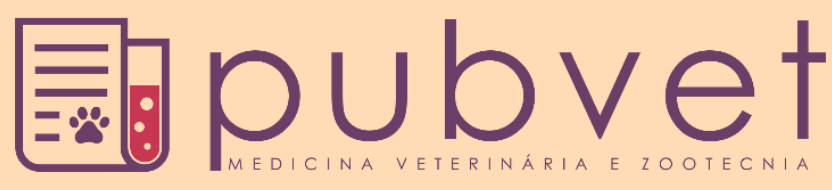

https://doi.org/10.31533/pubvet.v13n7a377.1-12

\title{
Relação humano-equino a partir da obra "O Gaúcho" de José de Alencar (1870)
}

\author{
João Paulo Novelletto Pisa ${ }^{1^{*}}$, Jorge Luiz Conte Tacito ${ }^{2}$, Denise Pereira Leme ${ }^{3 \bullet}$ \\ ${ }^{1}$ Discente do Programa de Pós-Graduação em Agroecossistemas da Universidade Federal de Santa Catarina e Núcleo de Equideocultura e Bem-Estar de \\ Equinos (NEBEq-LETA-UFSC), Departamento de Zootecnia e Desenvolvimento Rural, Florianópolis -SC Brasil. \\ ${ }^{2}$ Médico Veterinário Autônomo e NEBEq-LETA-UFSC, Departamento de Zootecnia e Desenvolvimento Rural. Florianópolis-SC Brasil. \\ ${ }^{3}$ Professora da Universidade Federal de Santa Catarina e NEBEq-LETA-UFSC, Departamento de Zootecnia e Desenvolvimento Rural. Florianópolis -SC Brasil. \\ *Autor para correspondência, E-mail: joaopisamdv@gmail.com
}

Resumo. Zooliteratura é o conjunto de obras literárias onde aparecem discussões sobre o "mundo animal", o que também pode ser chamado de Estudos Animais, com o objetivo de refletir sobre o outro, a animalidade, as relações entre humanos e animais. Um dos livros da literatura Brasileira é o Gaúcho de José de Alencar, com esta pode-se refletir sobre a relação humano-animal, a construção dessa relação, os princípios do personagem em relação ao cavalo e ainda no cenário do Pampa e na cultura gaúcha. O objetivo deste trabalho e analisar estas questões na obra e pensar em uma educação de bem-estar equino com uma visão mais local. Isto mostra que a Zooliteratura pode ser uma grande ferramenta para melhorar o bem-estar animal, pois, ela tem a capacidade de nos fazer ver e pensar sobre o outro e o contexto, para que se possa transformar a realidade.

Palavras chave: Bem-estar, cavalo crioulo, Rio Grande do Sul, pampa, zooliteratura

\section{Human-horse relation based on José Alencar's work “O Gaúcho”(1870)}

Abstract. Zooliterature, also known as Animal Studies, is a set of literature works that contain discussions about the "animal world", which reflects about the animal feature and the relationship between humans and animals. This area of literature studies has the capacity to make others reflect about the subject, and because of that it helps improving animals well-being. This work's goal is to analyse the human-horse relationship inside Jose de Alencar's book "O Gaúcho" and observe the beginning of this relation and what are the principal used by the main character regarding the horse, all that inside the scenario Pampa in the local culture, and with that develop an education of equine well being with a more local vision.

Keywords: Criollo horse, pampa, Rio Grande do Sul, welfare, zooliterature

\section{Relación humano-caballo basada en la obra de José Alencar "O Gaúcho" (1870)}

Resumen. Zooliterature, también conocido como Estudios de animales, es un conjunto de trabajos de literatura que contienen discusiones sobre el "mundo animal", que refleja la característica del animal y la relación entre humanos y animales. Esta área de estudios de literatura tiene la capacidad de hacer que otros reflexionen sobre el tema, y por eso ayuda a mejorar el bienestar de los animales. El objetivo de este trabajo es analizar la relación entre el hombre y el caballo dentro del libro "O Gaúcho" de José de Alencar y observar el comienzo de esta relación y cuáles son los principales utilizados por el carácter principal 
con respecto al caballo, todo eso dentro del escenario del Pampa, en la cultura, y con eso desarrollar una educación de bienestar equino con una visión más local.

Palabras clave: Bienestar, caballo criollo, Pampa, Rio Grande do Sul, zooliterature

\section{Introdução}

Zooliteratura é o conjunto de obras literárias onde aparecem discussões sobre o "mundo animal", o que também pode ser chamado de Estudos Animais. Um campo novo, com características de interdisciplinaridade e dialética, com o objetivo de refletir sobre o outro, a animalidade, as relações entre humanos e animais, sendo o elemento central, ele ou ela, humano ou animal, com isto as relações entre humanos e animais, animalidade e o devir-animal (Guida, 2011; Junqueira, 2013; Maciel, 2007).

A obra escolhida para este trabalho é "O Gaúcho" de José de Alencar, que mostra a relação humanoequino no contexto do Rio Grande do Sul e serve ainda para refletir sobre animalidade e o devir-animal. Luna \& Tadich (2019) fizeram um trabalho sobre a importância em acrescentar as relações de seres humanos e equinos em pesquisas; na conclusão desta revisão de literatura, chamaram a atenção para a identificação de problemáticas desta relação para compreender vulnerabilidades e pensar em educação de forma que respeite o contexto cultural do local a ser trabalhado.

Por conta disso, este artigo tem como objetivo analisar o livro "O Gaúcho", levando em consideração os trechos que relatam o bem-estar animal ligado à relação humano-equino e a construção dessa relação, já que com a literatura pode-se ter uma visão de uma estória contada; porém, terão como contrapartida uma revisão da literatura cientifica para verificar a validade de usar esta obra como verdade, além de uma interpretação da obra. Isto tudo tem com intuito de refletir sobre estratégias para a educação em bem-estar equino com uma visão mais regionalista, tendo assim a justificativa do uso da zooliteratura é a possibilidade de ver outro com empatia, para sua compreensão e pensamento de atitudes, para assim, melhorar o bem-estar animal.

\section{Material e métodos}

A versão escolhida para este artigo está disponível no site domínio público no formato PDF, por esta razão, serão citados os trechos com a localização do livro e do capítulo, não da página. Originalmente, o livro foi editado pela Ática em 1998 em sua 3 $3^{a}$ edição. A obra é composta por 4 livros; o peão com 14 capítulos, o Juca com 13, a Morena com 14 e o Upa! com 12 capítulos. Depois da leitura completa da obra, foram retirados trechos que condizem com os objetivos do livro, que são os comportamentos, emoções, bem-estar animal e relação humano-equino, para que seja buscado na literatura científica conhecimentos que aprovam ou não o que foi descrito no livro. Também, será utilizado da interpretação de texto, para ajudar na possível construção do afeto que o personagem Manuel Canho tinha pelos cavalos. Para finalizar, será utilizado os pensamentos que se obteve ao analisar a obra para refletir estratégias para a educação em bem-estar equino.

No livro "Ato da Leitura: uma teoria do efeito estético" de Wolfgang Iser traz ideias sobre a relação autor-leitor, em que é importante o autoconhecimento de quem lê, de que tipo de leitor ele é ou quer ser, para melhor aproveitar a leitura (Dias, 2017). Mas interpretação de texto não é uma tarefa fácil; um dos possíveis motivos apresentado por Massini-Cagliari (2001) é o fator escola, pois se espera que os alunos tenham o mesmo entendimento do professor, não verificar se realmente entendeu ou não o que foi lido, ou até sua própria visão e mesmo o professor deve seguir o que está no livro didático. Em poucos momentos há uma reflexão mais profunda e pessoal vinda da leitura, ou ainda, de forma interdisciplinar.

\section{Resultados e discussão}

Primeiramente, este livro se destaca o bioma pampa e a revolução farroupilha. O pampa é descrito no primeiro capítulo. $\mathrm{O}$ autor a define "Esta palavra originária da língua quíchua significa simplesmente o plaino; mas sob a fria expressão do vocábulo está viva e palpitante a ideia" (livro1; capítulo 1), e ainda coloca a imagem do potro indômito para comparação (livro 1; capítulo 1), este bioma ocupa $63 \%$ do território do estado Gaúcho e 2,1\% no total da área do Brasil, se caracteriza por um espaço grande e acidentado, com uma vegetação de gramíneas, ervas e plantas rasteiras e a palavra tem origem na língua Quechua e significa plano (Bencke et al., 2016). O livro se passa na época de revolução 
farroupilha que iniciou em setembro de 1835 até o fim de 1845, começou por causa do imposto sobre a carne-charque e teve o tom separatista. Seu fim se deu pelo manifesto poncho verde em setembro de 1845 por Bento Gonsalves (Dornelles, 2010) e José de Alencar (Alencar, 1978) também coloca este personagem para caracterizar, este fato histórico: "O coronel Bento Gonçalves da Silva, veterano da guerra da Cisplatina e comandante da fronteira de Jaguarão e Bagé, era então o homem mais respeitado em toda a campanha do Rio Grande do Sul. Franco e generoso, bravo como as armas, vazado na mesma têmpera de Osório e Andrade Neves, montando a cavalo como o Cid campeador, era Bento Gonçalves o ídolo da campanha (livro 1;capítulo 3)”. Ele foi um militar e líder revolucionário gaúcho, foi um dos líderes da revolução gaúcha, esteve na guerra da cisplatina, sendo nomeado coronel em 1829 e morreu em 1847 no município gaúcho de Guaíba (Telles, 2002); a revolução é mostrada mais nos livros 3 e 4 . Um dos principais destaques da obra é relação humano-equino, a raça que representa o Rio Grande do Sul é o Crioulo, que vem de tropa de equinos da Península Ibérica no século XVI, durante o período de colonização da América do Sul e as raças que o originaram é o Andaluz e Jacas, sendo selecionada por seleção natural por viverem livres, tornando-os animais mais rústicos e adaptados, sendo usados para lida do gado e até para guerras (Silva \& Farias, 2017), de tão importe foi criado uma lei estadual instituindo o dia do cavalo no estado (Lei ${ }^{\circ}$ 11.973), de 23 de setembro de 2003, em 14 de setembro, sendo este seu animal símbolo (Lei no 11.826, de 26 de agosto de 2002).

Mas o que marca o livro é a relação humano-animal e nisto o modo de lidar a partir do bem-estar equino está relacionado à ética, que é visto a ideia que o personagem Manuel Canho teve sobre este assunto. Em uma construção do conceito de bem-estar animal, Broom \& Molento (2004) definem como uma tentativa do indivíduo de se adaptar ao momento em que ele vive; já em uma revisão de Manteca et al. (2013), há a reflexão que é uma harmonia do animal em sua situação; ambos os trabalhos mostram a mensuração para avaliar o bem-estar animal. Neste caso, os que aferem as condições de status de estresse e condições de realizar seus comportamentos normais. Há diversos indicadores que ajudam avaliar o bem-estar equino, como o estado de condição corporal, sinais físicos como a presença de ecto e endo parasitas, tosse, lesões, claudicações, mau hálito, dor e febre, sinais comportamentais como as estereotipias, agressividade, reatividade em frente a situações e interações com outros equinos, mas também há os indicadores ambientais e de manejo (indiretos), que são os quesitos de manejo alimentar, disponibilidade de alimento e água, organização e manutenção do meio, armazenamento de insumos e o manejo geral, com isto pode-se verificar se há bem-estar satisfatório que contempla a saúde como conceito de integralidade e o bom desempenho do animal e bem-estar limitado, que contém problemas na presença dos indicadores, que podem levar o animal a sofrer e que precisam ser corrigidas (Mills \& Nankervis, 2005). Este livro contempla a parte de bem-estar equino. O personagem principal tinha uma boa relação com os animais, os deixava descansarem e comerem em momentos de lida, também domava de modo racional.

O Seguinte trecho faz a reflexão sobre a questão ética do bem-estar equino, como uma obrigação humana:

"Na opinião de Manuel, o cavalo e o homem contraíam obrigação recíproca; o cavalo de servir e transportar o homem; o homem de nutrir e defender o cavalo. Se um dos dois faltasse ao compromisso, o outro tinha o direito de romper o vínculo. O homem devia expulsar o cavalo, o cavalo devia deixar o homem" (Alencar, 1978).

No ano de 1978, em Bruxelas, se fez a Declaração Universal dos Direitos dos Animais que constitui uma série de leis que dizem que todos os animais têm direitos à vida e à dignidade e que os seres humanos são responsáveis por dar saúde física, mental e moral a eles. No artigo $10^{\circ}$ está escrito que nenhum animal pode ser usado para o divertimento das pessoas e que isto contradiz com a dignidade do animal (CFMV); porém, muitos equinos tem esta finalidade; portanto, se usa a ideia utilitarista do Peter Singer, em que o animal pode ser usado, desde que ele tenha o seu bem-estar garantido (Rouanet \& Carvalho, 2016).

No capítulo 2 do primeiro livro, tem-se uma passagem que mostra o Manuel Canho deixando o Morzelo em um momento de descanso, "Enquanto o morzelo se espojava na grama para desinteiriçar os músculos entorpecidos pelo arrocho da cincha, o viajante batia o fuzil, e tirava fogo para acender um molho de galhos secos" (Alencar, 1870), que pode ser interpretado como um momento de prazer 
para o cavalo que gera o bem-estar, de acordo com Boissy et al. (2007), bem-estar animal não é somente tirar as emoções negativas, mas proporcionar as positivas. Também é visto isto em outros trechos.

Duas vezes durante a noite apeou Manuel para oferecer fôlego ao brioso animal (livro 1; capitulo 9).

Que alegria ao vê-lo aproximar-se! Que afagos trocados entre os dois amigos! A Morena alongava o pescoço, estendia o focinho para os longes da campina; e roçava a espádua pelo gaúcho, vergando faceiramente o ombro, como se o convidasse a montar e partir. - Ainda não, Morena; coma e descanse primeiro, dizia Manuel, amimando-lhe o colo; há de ver o pequerrucho, mas a seu tempo (livro 1; capítulo 8).

Era a égua um inteligente animal; e depressa aprendera a linguagem pitoresca e simbólica inventada pelo gaúcho para suas relações sociais com a raça equina (livro 1; capítulo 8).

Puxando levemente a baia pela orelha, obrigou-a Manuel a pastar um trevo gordo e apetitoso que estofava as fendas de uma lapa. A Morena quis recalcitrar, mas cedeu submissa ao olhar imperioso do gaúcho (livro 1; capítulo 8).

Tão inteligente e elevado era o sentir dessa alma pelo brioso animal, que ele prezava como o companheiro e amigo do homem! Para ele, que devassava e entendia os arcanos da organização generosa, o cavalo se elevava ao nível da criatura racional. Tinha mais inteligência que muitas estátuas ermas de espírito; tinha mais coração que tantos bípedes implumes e acardíacos (livro 1; capítulo 11).

Há uma reflexão interessante proposta por Alencar:

Por que o animal selvagem e livre não corria onde o chamava o instinto com tamanha veemência? Tinha ele necessidade do homem, carecia do auxílio do amigo? ou uma força desconhecida o prendia à vontade superior que o tinha domado (livro 1; capítulo 9)?

No capítulo $\mathrm{V}$ do primeiro livro, tem-se uma égua de difícil lida, faziam uma aposta para quem conseguir montá-la.

Se não fosse tão ligeiro, o rapazinho não escaparia da fúria com que a égua se arrojara para mordê-lo; felizmente conseguiu ele alcançar o moirão, onde passou a laçada do cabresto, pondo-se fora de alcance.

Ninguém havia conseguido; porém, Manuel Canho o fez (Livro I; capítulo 6), utilizando de afetos positivos e carinho; porém, o primeiro momento que chama a atenção é que a quando se descreve que a égua conseguia compreender o Manuel Canho (...) Fita no semblante de Manuel a vista ardente $e$ sôfrega, dir-se-ia que a inteligente égua interrogava o pensamento do homem e queria compreendê-lo. E ainda. À medida que ela inalava o fluído magnético do olhar do gaúcho, uma expressão meiga e terna se refletia na pupila negra. Serenava a braveza e cólera acesa na próxima luta. O pêlo riçado ia-se aveludando, as ranilhas de suspensas pousavam sobre a relva, enquanto os flancos clássicos, alongando-se, perdiam a torção dos músculos, retraídos para o salto. O bruto entendia o homem. Quando Manuel aspirou às baforadas da fria rajada que vinha do deserto, a égua espreguiçou o lombo, recurvando o pescoço para estreitar o gaúcho; e um relincho de alegria arregaçou lhe o beiço. Um estudo atual mostrou que os equinos podem reconhecer emoções humanas. Foram realizados testes utilizando telas com expressões faciais humanas e sons de voz humana vindos de alto-falantes, tendo um estado congruente e incongruente, porém os animais ficaram mais tempo nos estado incongruente do que congruente quando a voz ouvida era do zelador, não de uma pessoa estranha e também responderam melhor nesta condição de incongruente (Nakamura et al., 2018), além dos equinos, outra pesquisa com caprinos concluiu que estes animais podem reconhecer as expressões faciais em seres humanos e ainda preferir as que são reconhecidas como positivas (Nawroth et al., 2018).

Um trecho que denota o modo racional que Canho tinha é este: Lentamente, a passo e passo, aproximou-se o gaúcho, até que pôde estender-lhe a mão sobre a espádua. A égua arisca arrufou-se de novo. Rápido foi o assomo; outra vez soara a seu ouvido, mais terno e plangente, o débil ornejo, ao 
tempo que a mão, instrumento e condutor d'alma humana, alisava-lhe a anca e a selada com um doce afago. Na verdade, não apenas mostra-se a relação de afeto com o animal, mas dá razão também, como este trecho. Em profundo silêncio assistiam os companheiros ao colóquio do bruto com o homem. Essa luta da razão com a força é sempre eloquente e admirável; aí patenteia-se o homem, rei da criação: o triunfo não pertence unicamente ao indivíduo, mas à espécie. José de Alencar coloca que antes de ser domada, possivelmente ela se rendeu ao amor e a gratidão.

Domada, ou antes, rendida ao amor e à gratidão, a baia aproximou-se do terreiro sacando com gentileza e elegância, como faria o mais destro corcel em luzida cavalhada.

O que mostra a racionalidade é a observação que ele teve da égua, que antes de tudo, notou que ela havia parido (livro 1; capítulo 7), mas além do entendimento houve a empatia, pois Sua alma comovida por sentimentos afetuosos pôs-se em contato com o instinto do animal; operou-se a transfusão; os intimos impulsos da recém-mãe se refletiram no coração terno do mancebo. Compreendeu o desespero, a saudade bravia pelo filho abandonado e a cólera terrivel contra aqueles que a tinham arrebatado às doçuras da amamentação (livro 1; capítulo 7). E mesmo depois de domada, a égua não teve uma boa relação de respeito com os outros, que não a respeitaram, assim como Manuel. Alguns dos peões se adiantaram para outra vez tentarem cavalgar o animal: não deram, porém, dez passos. Mal lhes pressentiu o intento, a égua, volvendo sobre as mãos de um tranco, e upando as ancas, arremessou tal cascata de coices, que afugentou os fanfarrões, obrigados a buscarem refúgio no alpendre (livro 1; capítulo 6). Mas, se fosse necessário, Manuel tinha atitudes mais rígidas com os equinos, mesmo com os desentendimentos entre eles, voltava ao normal depois. Posteriormente se discutirá a construção do afeto e a questão da forma de doma.

A estória não mostra uma situação de doma e treinamento propriamente ditas, mas sim, um caso de desafio para quem conseguisse montar a égua; porém, enquanto os outros personagens faziam de qualquer jeito, Manuel Canho utilizou de conhecimentos de comportamento e a não violência, mas isto mostra (além de outros trechos) que ele é domador racional, não tradicional gaúcho. Este tipo de doma e treinamento é conhecido desde a Grécia Antiga, feita pelo Xenophante (A arte do horsemanship), que coloca uma visão mais racional do que o que era feito pelo "Horse-Breaker" (quebradores de cavalo), que além de respeitar a etologia, havia o afeto, dizia que os equinos deviam ser acariciados em lugares que eles gostam, que não deve ser feito nada por medo, mas pela calma (Xenophon, 1893). Nos dias atuais, tem-se o modelo Join Up idealizado pelo Monty Roberts (Roberts, 2010), que conta em seu livro "O Homem Ouve Cavalos", um estudo realizado por Fowler et al. (2012) mostra a diferença da doma tradicional inglesa e da proposta por Monty Robert, sendo que as duas se mostraram eficazes; porém, os cavalos mais bem preparados fisiologicamente e psicologicamente eram do grupo do treinados pelo método Join UP, mas há críticas a ele, como no trabalho de Loftus et al. (2016) que constatou que os equinos nas demonstrações públicas do Monty Roberts eram negativamente afetados com um estresse fisiológico baixo a moderado, tendo como parâmetros da frequência cardíaca e respiratória a variação de frequência cardíaca, porém, em comparação a outras demonstrações públicas, eram menores, mas não há estressor psicológicos, então não se pode dizer que afeta o bem-estar dos equinos e em um trabalho feito por Muller et al. (2016) comentam a visão dele sobre o comportamento equino, os autores não pensam ser certo a pessoa se ver como um membro da espécie equina; criticam o conceito de liberdade, já que ainda os equinos fazem o que o ser humano quer, só que é reduzida a violência e o estresse; que depois de 20-30 minutos não há confiança, mas a eliminação da pressão, mesmo que realmente seja importante, a confiança na relação ser humano e equino deve ser feito com calma e tempo, não o mais rápido o possível; ele faz a punição positiva, não o reforço positivo, já que ele utiliza de meios que podem causar medo aos equinos, pois persegue e faz sinais de ameaça. Estes autores chamam a atenção para que as pessoas olhem com outra forma este método de doma e treinamento, que é muito popular. Monty usou de experiências pessoais e saberes populares, não estudou de fato a ciência do comportamento equino, mas tanto os cientistas podem aprender com os domadores práticos como eles podem aprender com a ciência (Farmer-Dougan \& Dougan, 1999). Kosby et al. (2017) criticam o método racional, por este não preparar o cavalo para a lida campeira, em comparação a doma tradicional gaúcha.

Há diversos trabalhos na literatura científica que aborda a questão de identidade do gaúcho pampeiro, como Feijó (1983) descreve a sua lida, seu trabalho com o gado e outros animais, sua relação com o 
cavalo crioulo, os rodeios, sua vida e costumes, que vão passando de geração em geração, já Murari (2015) mostra que José de Alencar usou as características de senso de moralidade, valores da família, afeto aos cavalos, coragem, ódio ao povo castelhano, ser vingativo e o patriarcado para compor o personagem Manuel Canho, que seria mais uma variante de herói, já Arendt \& Freitas (2017) também mostram a aversão ao estrangeiro, a relação com os animais; porém, existe o sentimento do ser humano se sentir inferior aos animais, a questão da linguagem e da música, mas para eles a relação com os equinos é o que mais se destaca na obra que tem um significado regionalista. Melo (2008) ressalta o amor pelos cavalos como característica principal do personagem, além da relação com a natureza, valentia e a força. Por fim, Zalla (2010) faz um ensaio crítico a esta imagem proposta por José de Alencar, porém, assim como os outros autores, este destaca a relação que ele tinha com os cavalos.

Um modo de notar a relação dos animais e os humanos são os adjetivos que denotam os animais, José de Alencar utilizou de diversos adjetivos aos equinos que mostram as qualidades, comportamentos e a relação humano-animal, como brioso, indômito, generoso, bruto, lindo, formosa besta, chiquita, árdego, guapa estampa, elevado, fogoso, inteligente e soberbo, porém, o que mais representa a cultura gaúcha é o pingo, que o autor escreveu como "Quando ele diz "meu pingo" é como se dissesse meu amigo do coração, meu amigo leal e generoso" (livro I; capítulo 2). Mas além deles, os animais tiveram nomes, o Morzelo, a Morena e o Juca.

Há várias frases que mostram a importância do cavalo para a cultura gaúcha e para o personagem protagonista: Canho estava gostando de ouvir o elogio feito a seu animal: o cavalo é uma das fibras mais sensíveis do coração do gaúcho (livro 1; capítulo 2). Mas, estes animais podem ser vistos como membros da família e amigos: Havia entre o gaúcho e os cavalos verdadeiras relações sociais. Alguns faziam parte de sua família; outros eram seus amigos; aos mais tratava-os como camaradas ou simples conhecidos (livro 1; capítulo 7). Tinha o gaúcho inventado uma linguagem de monossílabos e gestos, por meio da qual se fazia entender perfeitamente dos animais. Um hup gutural pungia mais seu cavalo do que a roseta das chilenas; não carecia das rédeas para estacar o ginete à disparada: bastava-lhe um psiu (livro 1; capítulo 7). O peixe careca d'água, o pássaro do ambiente, para que se movam e existam. Como eles, o gaúcho tem um elemento, que é o cavalo. A pé está em seco, faltam-lhe as asas. Nele se realiza o mito da antiguidade: o homem não passa de um busto apenas; seu corpo consiste no bruto. Uni as duas naturezas incompletas: este ser híbrido é o gaúcho, o centauro da América (livro 1; capítulo 7). - Fujamos deste mundo infame! Vamos ao deserto, onde o homem é fera como o tigre. Lá ninguém há de ser enganado pelo amigo e traído pela mulher. Cada um só conta consigo; se quer um irmão tem o seu cavalo fiel (livro 4; capítulo 11). Com estas frases, nota-se que o cavalo tem é uma peça fundamental na vida de um gaúcho, em que tem relações de afeto de amizade e até familiar e promove relações sociais, como visto anteriormente no desafio de montar na égua (Morena).

Manuel mostrou a dor do luto quando os animais morriam.

- Morreste, meu amigo; chegou tua hora. A nossa, a de teu companheiro de infância e de teus camaradas, talvez não esteja longe; talvez que vamos ter contigo muito breve! Mas eu sempre pensei que a ti, o bravo dos bravos, estava reservada a fortuna de morrer combatendo, e não pela mão traiçoeira de um malvado!... Morreste por dedicação; mas serás vingado, amigo! Eu juro sobre tua sepultura; e esses dois irmãos juram comigo (livro 3; capítulo 10).

- Assim devia ser!... balbuciaram seus lábios frouxos. Vivemos juntos, morreremos juntos, no mesmo dia. Morzelo, nosso velho amigo, foi o primeiro: deixou-nos esta manhã. Nós ficamos para vingá-lo; ele deve estar contente. Juca, a esta hora talvez já esteja com o padrinho; já terá conhecido o pai e o mano. A bala sem dúvida traspassoulhe o coração, porque não soltou um gemido, não chamou nem por ti, nem por mim; foi mais feliz; não sofreu como tu, Morena (livro 3; capítulo 11)!...

Todavia, esta relação promove o Devir-Animal, um conceito utilizado nas ciências humanas e na zooliteratura, que pode ser um meio de explicar a animalidade, pois, devir tem em seu significado as mudanças ou transformações que algo ou alguém passa, e na questão dos animais, esta transformação está ligada às ações humanas, este conceito foi proposto por Guattari \& Deleuze (Guida, 2011), podese pensar ainda, que o devir animal pode ser a causa de problemas comportamentais, por muito delas, 
como estereotipias, está ligado com a vida contemporânea que causa tédio, por um manejo errado, vida privada ou solitária (Broom \& Fraser, 2010) é uma mudança que o ser humano provocou nos animais. A seguir duas frases que mostram o devir-animal.

Enfim o cavalo era para o gaúcho um próximo, não pela forma, mas pela magnanimidade e nobreza das paixões. Entendia ele que Deus havia feito os outros animais para vários fins recônditos em sua alta sabedoria; mas o cavalo, esse Deus o criara exclusivamente para companheiro e amigo do homem (livro 1; capítulo 7).

$O$ contato de nossa raça desvanece no animal o espanto selvagem que sente ainda o mais intrépido na presença do rei da criação. A amizade do homem inspira, sobretudo ao cavalo, uma emulação generosa, um heroísmo admirável. O Bucéfalo de Alexandre, o Morzelo de César, e o Orélia do rei D. Rodrigo, foram dignos dos heróis a quem serviram (livro 3; capítulo 2).

Se o homem é o rei da criação, o cavalo serve-lhe de trono. Veículo e arma ao mesmo tempo, ele nos suprime as distâncias pela rapidez, e centuplica nossas forças. Para o gaúcho, especialmente para o filho errante da campanha, esse vínculo se estreita (livro 1; capítulo 7).

Se for pensar, os equinos nasceram para ser equino, viverem do jeito e da natureza deles, porém, os seres humanos os pegaram para si, modificando sua vida e seu habitat, dando características para praticar cada esporte e desempenhar trabalhos, mas, antes de tudo, o tornou um animal doméstico e de estimação, talvez, na natureza os equinos fugiriam dos humanos, por ser uma relação presa-predador (corrigidas (Mills \& Nankervis, 2005); porém, houve a ressignificação do ser animal e da existência equina, isto é devir-animal. Um exemplo do cinema é o Leão Alex dos filmes de Madagascar da Dreamwoks (2005, 2008, 2012), ele é um leão, mas por viver num zoológico e ser estrela dele, teve dificuldades quando foi para a natureza e reencontrou sua família e teve que brigar para se manter no grupo. Mesmo sendo um leão, não era um leão que se comportava como um leão, houve uma transformação provocada pela ação humana, formando sua animalidade, que é diferente do natural.

Mas para Manuel Canho, os cavalos continuavam livres, não podendo para ele, imaginar o custo destes animais:

- Vale muito, nem digo o contrário. Mas a égua não me pertence. - De quem é então? - De ninguém. É livre. - Está zombando? - Dou-lhe minha palavra. É livre, tão livre como eu, disse o gaúcho com firmeza.

- Bem: neste caso, eu a tomarei para mim. - Com que direito? O caçador grunhiu uma espécie de riso, que insuflou-lhe as ventas largas. - Vê aquela onça? Esta manhã era mais livre do que a égua. - Perca a esperança, que a égua não há de ser sua. Por que então? Fitando no caçador um olhar límpido e sereno, respondeu o gaúcho com pausa: - Porque eи não quero.

Forma-se um paradoxo, pois, mesmo que Canho considera um animal livre, o doma e tem equinos para si, talvez, a liberdade para ele tem como a definição respeitar a natureza e tratar com afeto, embora não referiu os cavalos como propriedade (como outros personagens), mas como irmão, amigos e família, mesmo assim, ocorreu o devir-animal, pois eles mudaram a sua animalidade, de seres realmente livres para seres considerados com afetos de amizade e familiar.

Uma das oportunidades que a zooliteratura dá é a percepção para o outro, seja humano ou animal, no caso do ser humano, muitas vezes pode-se conhecer mais a história dele e como foi à construção para que tenha certos afetos e modos com o animal, este livro aborda com profundidade a vida de Manuel Canho, como também a sociedade em que ele vive, por isso, pode-se pensar na construção do afeto que ele tem pelos equinos. Para ser entendida, a obra como um todo deve ser lida e compreendida, mas a parte que tem mais importância para compreensão deste assunto está no livro 2, nos capítulos 2, 3 e 4, sugere-se a leitura destes trechos com mais atenção. Em resumo, Manuel Canho perdeu o pai de forma violenta, queria vingança da morte do pai, mas sua única lembrança que tinha do pai é que era ginete, assim, quis seguir os passos do seu pai. Porém, no decorrer da estória, percebe-se que há uma desistência 
de viver em sociedade, encontrando nos cavalos afetos bons, tendo a sua infância mais em contato com os animais do que com as pessoas:

Esta é a gineta que eu uso e aprendi de meu pai. Ela faz do cavalo um amigo e não um cangueiro. Mas também, senhores, se o bicho é mau, da casta que for, de dois ou de quatro pés, fiquem certos que no continente também os sabemos ensinar. Caso haja por aí algum deste lote, minha gente, botem-no para cá e verão (livro 1; capítulo 7).

Desde criança lidava Manuel com animais; fora esse o ofício de seu pai; não havia em toda a campanha do Rio Grande amansador de fama que se comparasse com o João Canho. o que mais se admirava no moço gaúcho não era contudo a destreza, na qual excedia de muito ao pai; porém sim a dedicação que ele tinha à raça hípica (livro 1; capítulo 7).

Não era possível que Manuel abandonasse o Morzelo, seu amigo de infância, o confidente de suas mágoas, o companheiro fiel e dedicado de João Canho (livro 3; capítulo 10).

O mais, o dinheiro e a mulher, acha-se a cada canto; porém o cavalo, que nos entende, e se liga ao nosso destino no trabalho e na guerra, na vida e na morte, este, uma vez perdido, custa a achar outro, quando se acha (livro 3; capítulo 8).

Foi deste modo que a alma do gaúcho emigrou, da família primeiro e depois da sociedade humana, para a raça bruta que simbolizava a seus olhos a fidelidade, a dedicação e a nobreza. Seu coração ermo e exilado buscou naturalmente na comunhão dessas criaturas a correspondência dos sentimentos inatos ao homem (livro 2; capítulo $5)$.

Assim o primeiro símbolo do amor que se gravou n'alma de Manuel não foi uma figura humana, porém o vulto de um corcel (livro 2; capítulo 5).

Para melhor entendimento, pode-se usar outros livros de literatura, como a Amy de Heartland (Brooke, 2003) que herdou o dom da mãe em domar cavalos, e continuou com isto depois que ela morreu. Em viagens de Gulliver, Swift (2012) faz uma grande sátira, em que o personagem principal vai em uma ilha em que os equinos são os seres racionais e os humanos são os irracionais, no fim da história, ele queria viver com os equinos e não mais com os humanos. Uma obra da literatura brasileira que se aproxima desta é Vidas Secas de Gracialiano Ramos (2006), pois a vida social é praticamente a mesma, são pessoas que foram deixadas de lado pelo poder público, que não os deu educação, saúde, moradia, um ambiente de justiça e de conversa, tornando o afeto do ódio e da vingança o status quo, tanto Manuel Canho, como Fabiano se viam como animais e tinham os animais (no caso a Baleia em Vidas Secas), como os únicos meios de ter afetos positivos, embora há uma égua na história de Ramos, em que mostra o status quo da violência, como se fosse pela doma mostrar a superioridade e masculinidade. Em Dom Segundo Sombra de Ricardo Guiraldes (Guiraldes, 1997) também mostra a realidade do pampa e este status quo, porém, como o personagem estava nesta cultura da violência como normalidade, tinha como forma de doma a tradicional, em que muitas vezes se emprega a violência e $o$ não conhecimento do animal, mas também, não foi dada a oportunidade de pensar diferente e conhecer mais da etologia equina.

O que define o modo de Manuel Canho lidar com os animais e a sua não presença na sociedade, que algumas vezes tratava com estranheza o seu modo de lidar com os animais: - Mas por que razão não quer você vir conosco, Manuel? O gaúcho calou-se; o que ele sentia, os outros não poderiam compreendê-lo. - Algum dos senhores abandonaria seu irmão e seu amigo quando ele está a expirar? - Acima de tudo a pátria! - Minha pátria é a campanha onde corre meu cavalo (livro 3; capítulo 13). É necessário advertir que havia um pudor extremo na afeição que Manuel votava aos animais. Se o encontrassem a abraçar algum e a amimá-lo, como já tinha acontecido, corava. Era a sós que as expansões de seu coração desafogavam-no livremente (livro 2; capítulo 6). Coração para uma raça bruta, músculo apenas para sua própria espécie e até para sua família. Quanto se expandia em amor e dedicação com os animais, seus prediletos, tanto se retraía com frieza e indiferença ante as mais doces afeições de sangue que o cercavam. Não se explica semelhante aberração. Talvez que algumas 
particularidades da infância de Manuel aventem a razão desse teor d'alma tão avesso da natureza (livro 2; capítulo 2). - Nem eu digo o contrário. Todos os amigos juntos não valem o Morzelo que foi de meu pai; mas os homens, ao menos, não enganam tanto (livro 1; capítulo 7)! - O homem tem partes com o diabo! Cruzes! (livro 1; capítulo 7). Vê-se que por mais que a relação não era perfeita, era um modo de fuga da sociedade, que os impedia de ser gente, tendo assim, mais afinidade com os animais, que não eram apenas amigos, era família, eram irmãos. Porém; nem todas as pessoas viam assim, por viverem no status quo que foi dado a elas, causando preconceito ou até o afeto da inveja, por não terem o mesmo afeto de amor que Canho tinha, apenas podiam sentir o afeto do ódio.

José de Alencar resume à "Formação do Centauro":

A alma do menino foi-se moldando naturalmente pelo que admirava. A vida de peão inspirava-lhe entusiasmo. O baguá era para ele o símbolo da força e da fereza; domar o cavalo selvagem, o filho indômito dos pampas, significava o maior triunfo a que podia aspirar o homem. $O$ amansador era o rei do deserto. Ao mesmo tempo, sempre em contato com a raça equina, revelava-se a seu espírito infantil as grandes qualidades desse animal de paixões nobres e generosas, capaz das maiores dedicações, intrépido, sóbrio, leal, paciente na ocasião do sacrifício, impetuoso no momento do perigo. $O$ menino sentia em si essa mesma natureza, o germe daquelas virtudes, e assim gradualmente ia-se operando em seu caráter uma espécie de identificação entre o cavalo e o cavaleiro. Era a misteriosa formação do centauro (livro 2; capítulo 2).

Com a percepção da construção do afeto que Manuel Canho tinha com os cavalos, assim, como a compreensão do contexto social que ele vivia e com a ajuda da visão dos outros livros, pode-se pensar em estratégias para a educação em bem-estar equino, de forma mais regionalizada (Luna \& Tadich, 2019). Porém, antes de começar é necessário salientar que o livro "O Gaúcho" de José de Alencar foi publicado no ano de 1870, praticamente 150 anos atrás. Com isto, muita coisa mudou e com ele os conhecimentos e práticas aceitáveis socialmente. Por isso não dá para pensar no gaúcho de José de Alencar, mas um devir-gaúcho, que compreende o modo contemporâneo de viver o cavalo. Neste pensamento há o artigo de Kosby et al. (2017) descrevem o Centauro de Motocicleta como a doma racional e o manejo do PRV (Pastoreio Racional Voisin) mudam a caracterização do gaúcho e como servem para domesticar, não só os animais, mas o humano também. Na atualidade há materiais como o Manual de Boas-Práticas para o bem-estar Animal em prova equestres (2015) e o Manual de BoasPráticas de Manejo em Equideocultura (2017), publicados pelo Ministério da Agricultura, Pecuária e Abastecimento. Talvez, esta mudança veio com uma visão de construção de afeto diferente e mais oportunidades de estudo, transformando o status quo. Em 1872 (2 anos depois da publicação do livro) o nível de analfabetismo no Rio Grande do Sul era de 74,6\%, no censo de 200 passou para 9,4\% (pessoas acima de 5 anos), e o estado estava nas menores taxas em relação ao resto do país (Ferraro \& Kreidlow, 2004), já em 2010 a taxa de alfabetização de pessoas maiores de 15 era de 95,5\%, a taxa de escolarização em 2017 (pessoas matriculadas em escolas) era de 97,5\% para o ensino fundamental e 62,6\% para o ensino médio (Atlas Socioeconômico - RS, 2017). Não basta apenas estar na escola, deve aprender conhecimentos interdisciplinares de bem-estar e ética animal. Em um estudo em grades curriculares de cursos de veterinária do Brasil (2016), foi visto que 37,97\% não possuem nenhuma destas disciplinas, 46,83\% tinham a disciplina de Bem-Estar animal e 8,22\% de bioética (Uliana et al., 2018).

Então, a possível estratégia em pensar na educação para o bem-estar de cavalos é o reconhecimento do passado, a estimulação de afetos e a busca maior pelo conhecimento sobre bem-estar animal e a filosofia ética, não somente para os graduandos da área, mas para todos, desde a infância, afim de estimular maior consciência das capacidades cognitivas, etologia e questões éticas, a partir da realidade cultural local, para estimular a empatia com os equinos e com as pessoas também, um método seria utilizar da literatura, como Arruda (2017) realizou um trabalho com crianças e adolescentes de 10 a 15 anos em uma escola rural em Cachoeira Grande sobre zooliteratura no gênero de Fábula, foi um trabalho muito importante para o bem-estar animal, pois os alunos tinham uma boa relação com os equinos e caninos, por ser mais do seu trabalho, porém com porcos, aves, gatos, silvestres e outros são ignorados e tem uma visão negativa da relação humano-animal, mesmo que o ambiente deles sejam em contato com os animais, sendo assim, este projeto desenvolvido ajudou na conscientização e reflexão crítica sobre o modo que eles lidavam com os animais. 
Para educar, é importante conhecer a opinião das pessoas, como na pesquisa de Simon et al. (2018) em que mostram a visão das pessoas do sofrimento dos equinos em determinados esportes e treinamentos; $57,1 \%$ acham que os equinos não sofrem na gineteada, $75,6 \%$ não sofrem na doma, 76,8\% não sofrem na prova do laço, $75,8 \%$ não sofrem na paleteada e $90,9 \%$ não sofrem na prova de tambores. Em sua conclusão, sugerem mais conscientização para o bem-estar animal.

Além das questões de bem-estar animal, tem as questões éticas e legais, como mostram Ritz \& Cardoso (2014) sobre a gineteada, pois as pessoas têm o direito ao acesso a cultura e expressar sua cultura, da mesma forma que os animais também possuem direitos e citam leis que proíbem o uso de instrumentos que causam danos físicos aos animais (A Lei Estadual $\mathrm{n}^{\circ} 11.719 / 02$ ) e Regulamento Campeiro do Movimento Tradicionalista Gaúcho que proíbe a utilização da espora do tipo nazarena, mas os autores frisam que isso não impede o sofrimento do animal, pois a prática que é considerada violenta por si só. Este assunto, como mesmo mostra nas considerações finais, é um dilema ético e jurídico, que pode ser utilizado para na reflexão para a educação, talvez, na busca de um meio termo, que não se deixe a cultura de lado, mas que os animais não sofram, como propõe os autores.

Portanto, uma estratégia para a educação em bem-estar de equinos é a utilização de livros de literatura, com uma conversa ampla e democrática, em que se tenha os saberes da ciência, que se respeite as pessoas e suas visões e que seja estimulada mais ainda a empatia, como o livro Beleza Negra da escritora Anna Sewell (Sewel, 2015), a obra conta a história de um cavalo no ponto de vista dele, mas na verdade é um convite para ver o outro e sua história também, seja animal ou ser humano, para que assim as pessoas possam compreender a lógica do outro e intervir a partir dela, com respeito e através da educação. A partir da obra literária "O Gaúcho" de José de Alencar, pode-se aprender mais sobre o bem-estar equino, relação humano animal e sua construção, com isto, teve-se a oportunidade de refletir estratégias para a educação em bem-estar equino. Isto mostra que a Zooliteratura pode ser uma grande ferramenta para melhorar o bem-estar animal, pois, ela tem a capacidade de nos fazer ver e pensar sobre o outro e o contexto, para que se possa transformar a realidade.

\section{Agradecimentos}

O presente trabalho foi realizado com apoio da Coordenação de Aperfeiçoamento de Pessoal de Nível Superior -Brasil (CAPES) - Código de Financiamento 001.

\section{Referências bibliográficas}

Alencar, J. (1978). O gaúcho. São Paulo, Brasil: Ática.

Arendt, J. C. \& Freitas, M. A. d. A. (2017). Os pingos de Alencar: pervasividade regionalista e reconfigurações fronteiriças de O gaúcho até délibáb. Contexto, 1(31):163-198.

Arruda, K. B. (2017). A fábula na sala de aula: a gênese, o gênero e a zooliteratura. Paper presented at the IV Congresso Nacional de Educação, João Pessoa, Paraíba.

Atlas Socioeconômico-RS (2017). Alfabetização. Disponível em < https://atlassocioeconomico.rs.gov.br/alfabetizacao> Acessado em 3 de Maio de 2019.

Bencke, G. A., Chomenko, L. \& Sant'anna, D. M. (2016). O que é o Pampa? In L. Chomenko \& G. A. Bencke (Eds.), Nosso Pampa Desconhecido (pp. 17-27). Porto Alegre, Rio Grande do Sul, Brasil: Fundação Zoobotânica do Rio Grande do Sul.

Boissy, A., Manteuffel, G., Jensen, M. B., Moe, R. O., Spruijt, B., Keeling, L. J., . . Langbein, J. (2007). Assessment of positive emotions in animals to improve their welfare. Physiology \& Behavior, 92(3):375-397.

Brooke, L. (2003). Heartland: Sooner or later. New York, USA: Scholastic.

Broom, D. M. \& Fraser, A. F. (2010). Comportamento e bem-estar de animais domésticos. São Paulo, Brasil: Editora Manole.

Broom, D. M. \& Molento, C. F. M. (2004). Animal welfare: concept and related issues-review. Archives of Veterinary Science, 9(2):1-11.

Dias, K. C. B. (2017). Resenha: O ato da leitura de ISER, Wolfgang. Fragmentos de Cultura, 27(3):445458. 
Dornelles, L. L. (2010). Guerra Farroupilha: considerações acerca das tensões internas, reivindicações e ganhos reais do decênio revoltoso. Revista Brasileira de História \& Ciências Sociais, 2(4):168178.

Estado do Rio Grande do Sul. Assembleia Legislativa. Constituição (2003). Lei $N^{o} 11.973$, de 23 de Setembro de 2003. Porto Alegre, RS.

Estado do Rio Grande do Sul. Assembleia Legislativa. Constituição (2002). Lei $N^{o} 11.826$, de 26 de Agosto de 2002., Porto Alegre, RS.

Estado do Rio Grande do Sul. Assembléia Legislativa. Constituição (2002). Lei $N^{o} 11.719 / 02$, de 7 de janeiro de 2002., Porto Alegre, RS.

Farmer-Dougan, V. A. \& Dougan, J. D. (1999). The man who listens to behavior: folk wisdom and behavior analysis from a real horse whisperer. Journal of the Experimental Analysis of Behavior, 72(1):139-149. doi: http://dx.doi.org/10.1901/jeab.1999.72-139.

Feijó, A. (1983). Gaúchos: Os centauros do Pampa. Geográfica Universal, 10740-49.

Ferraro, A. R. \& Kreidlow, D. (2004). Analfabetismo no Brasil: configuração e gênese das desigualdades regionais. Educação \& Realidade, 29(2):179-200.

Fowler, V., Kennedy, M. \& Marlin, D. (2012). A comparison of the Monty Roberts technique with a conventional UK technique for initial training of riding horses. Anthrozoös, 25(3):301-321. doi: http://dx.doi.org/10.2752/175303712x13403555186217.

Guida, A. M. (2011). Literatura e estudos animais. Raído, 5(10):287-296.

Guiraldes, R. (1997). Dom Segundo Sombra. Porto Alegre, Rio Grande do Sul: L\&pm Editores.

Junqueira, M. A. (2013). O animal escrito-um olhar sobre a zooliteratura contemporânea. Revista do Programa de Estudos Pós-Graduados em Literatura e Crítica Literária, 11301-306.

Kosby, M. F., Lima, D. V. \& Rieth, F. M. S. (2017). Centauros de motocicleta: o cavalo como testemunha do "processo domesticatório" do gaúcho. Horizontes Antropológicos, 23(48):197-223. doi: http://dx.doi.org/10.1590/s0104-71832017000200009.

Leme, D. P., Silva, E. L., Vieira, M. C. , Buss, L. P. (2017). Manual de Boas-Práticas de Manejo em Equideocultura. Brasil. Ministério da Agricultura, Pecuária e Abastecimento. Secretaria de Mobilidade Social, do Produtor Rural e Cooperativismo. - Brasília : MAPA/ACE/CGCS, 50p.

Loftus, L., Marks, K., Jones-McVey, R., Gonzales, J. \& Fowler, V. (2016). Monty Roberts' public demonstrations: Preliminary report on the heart rate and heart rate variability of horses undergoing training during live audience events. Animals, 6(9):55-68. doi: http://dx.doi.org/10.3390/ani6090055.

Luna, D. \& Tadich, T. A. (2019). Why Should Human-Animal Interactions Be Included in Research of Working Equids' Welfare? Animals, 9(42):1-15.

Maciel, M. E. (2007). Zoopoéticas contemporâneas. Remate de Males, 27(2):197-206.

Manteca, X., Silva, C. A., Bridi, A. M. \& Dias, C. P. (2013). Bem-estar animal: conceitos e formas práticas de avaliação dos sistemas de produção de suínos. Semina: Ciências Agrárias, 34(2):42134229.

Massini-Cagliari, G. (2001). Interpretação de textos: alguns aspectos teóricos e práticos. Linha D'Água(15):17-29.

Melo, E. S. C. (2008). A figura histórica e ficcional do gaúcho: o gaúcho, de josé de alencar, e perseguição e cerco a juvêncio gutierrez, de tabajara ruas. Master of Science, Pontifícia Universidade Católica do Rio Grande do Sul, Porto Alegre, Rio Grande do Sul.

Mills, D. \& Nankervis, K. (2005). Comportamento Equino- Princípios e prática. São Paulo, Brasil: Editora Roca.

Minchillo, C., Leschonski, C., Maldonado, F., Buss, L. P. \& Teixeira, R. R. (2015). Manual de BoasPráticas para o bem-estar Animal em competições equestres. Ministério da agricultura, pecuária e abastecimento, Brasilia. 
Muller, P., Chrzanowska, A. \& Pisula, W. (2016). A critical comment on the Monty Roberts interpretation of equine behavior. Psychology, 7(4):480-487. doi: http://dx.doi.org/10.4236/psych.2016.74049.

Murari, L. (2015). "Um eugênico, enfim": o gaúcho como tipo antropológico na literatura e no discurso social brasileiro. Topoi, 16(31):596-615. doi: http://dx.doi.org/10.1590/2237-101x016031010.

Nakamura, K., Takimoto-Inose, A. \& Hasegawa, T. (2018). Cross-modal perception of human emotion in domestic horses (Equus caballus). Scientific Reports, 8(1):1-9.

Nawroth, C., Albuquerque, N., Savalli, C., Single, M.-S. \& McElligott, A. G. (2018). Goats prefer positive human emotional facial expressions. Royal Society Open Science, 5(8):1-8.

Ramos, G.. Vidas Secas. 2006. 99. ed. Rio de Janeiro: Civilização Brasileira.

Ritz, C. S. P. \& Cardoso, W. M. (2014). Gineteadas: exercício da cultura regional x dignidade do animal. Paper presented at the Semana acadêmica fadisma entrementes, Santa Maria, Rio Grande do Sul, Brasil.

Roberts, M. (2010). O homem que ouve cavalos. São Paulo, Brasil: Bertrand Brasil.

Rouanet, L. P. \& Carvalho, M. C. (2016). Ética e direito dos animais. Florianópolis, Santa Catarina, Brasil: Universidade Federal de Santa Maria.

Sewel, A. (2015). Beleza Negra. Dracacena, São Paulo, Brasil: Balneário Rincão.

Silva, B. P. \& Farias, C. V. S. (2017). Cadeia de criação e comercialização do cavalo Crioulo no Rio Grande do Sul. Revista Teoria e Evidência Econômica, 23(48):1-25. doi: http://dx.doi.org/10.5335/rtee.v23i48.7360.

Simon, V., Zago, L., Magalhães, D. R., Levrino, G. A. M., Sañudo, C. \& Kirinus, J. K. (2018). O rodeio como uma prática esportiva de identidade cultural na região Sul do Brasil. PUBVET, 12(11):1-6. doi: http://dx.doi.org/10.31533/pubvet.v12n11a201.1-6.

Swift, J. (2012). Viagens de Gulliver. 15. ed. São Paulo: Scipione, 2012. 152 p. (Reencontro literatura). Tradução de: Cláudia Lopes.

Telles, J. (2002). Farrapos: a guerra que perdemos. Porto Alegre, Rio Grande do Sul, Brasil: Martins Livreiro.

Uliana, D., Carvalho, D. \& Bonamigo, E. (2018). Bioética e bem-estar animal nos cursos de medicina veterinária brasileiros. Revista Brasileira de Bioética, 141-16.

Xenophon, M. M. (1893). The art of horsemanship. Boston, USA: Little, Brown, And Co.

Zalla, J. (2010). O gaúcho de José de Alencar e a nação como projeto:"romantismo político" à brasileira? Nau Literária, 6(2):1-11.

Recebido: 25 de junho, 2019.

Aprovado: 23 de junho, 2019.

Publicado: 8 de agosto, 2019.

Licenciamento: Este artigo é publicado na modalidade Acesso Aberto sob a licença Creative Commons Atribuição 4.0 (CC-BY 4.0), a qual permite uso irrestrito, distribuição, reprodução em qualquer meio, desde que o autor e a fonte sejam devidamente creditados. 